\title{
Arrugas (2011) de Ignacio Ferreras. La enfermedad de Alzheimer a través del cómic y del cine
}

\section{Miguel ABAD VILA¹, María Blanca MAYOR SERRANO²}

${ }^{1}$ Hospital Comarcal de Verín. Xerencia de Xestión Integrada de Ourense, Verín e O Barco de Valdeorras (España). ${ }^{2}$ Especialista en comunicación médico-sanitaria. Valencia (España).

Autor para correspondencia: Miguel Abad Vila. Correo electrónico: mabadvila@gmail.com

Recibido el 11 de marzo de 2019; aceptado el 3 de abril de 2019.

Cómo citar este artículo: Abad Vila M, Mayor Serrano MB. Arrugas (2011) de Ignacio Ferreras. La enfermedad de Alzheimer a través del cómic y del cine. Rev Med Cine [Internet] 2019;15(4): 237-47

DOI: http://dx.doi.org/10.14201/rmc2019154237247

\section{Resumen}

La enfermedad de Alzheimer constituye la demencia más común entre las personas mayores. Sus devastadores efectos no se limitan exclusivamente a los enfermos, sino que afectan también a sus familiares y cuidadores. Debido a su elevado grado de dependencia, durante las etapas finales de la enfermedad muchos de estos pacientes pueden necesitar ser institucionalizados. Arrugas (2011) de Ignacio Ferreras, inspirada en el exitoso cómic homónimo (2007) del historietista Paco Roca, nos muestra las vicisitudes que su protagonista, Emilio, ha de atravesar cuando su familia decide ingresarlo en una residencia de ancianos y los vínculos que establece con otros internos, especialmente el desvergonzado y nihilista Miguel.

Palabras clave: enfermedad de Alzheimer; vejez; residencia para ancianos; amistad; cómic; cine.

\section{Arrugas (2011) by Ignacio Ferreras. Alzheimer's disease through comic and cinema}

Summary

\begin{abstract}
Alzheimer's disease is the most common dementia among the elderly. Its devastating effects are not limited exclusively to the sick, but also affect their relatives and caregivers. Due to their high degree of dependence, during the final stages of the disease many of these patients may need to be institutionalized. Arrugas (2011) by Ignacio Ferreras, inspired by the hit comic of the same name (2007) by the cartoonist Paco Roca (2008), shows us the vicissitudes that his protagonist, Emilio, has to go through when his family decides to enter him in a nursing home, and the links he establishes with other inmates, especially the shameless and nihilist Miguel.
\end{abstract}

Keywords: Alzheimer's disease; elderly; nursing home; friendship; comic; cinema. 
"Somos lo que recordamos y lo que los demás recuerdan de nosotros" Miguelanxo Prado, dibujante de cómics

Ficha técnica

\section{Título: Arrugas.}

Título Original: Arrugas.

Otros títulos: Rugas (Brasil, Portugal), La Tête en l'air (Francia, Canadá), Ráncok (Hungría), Rughe (Italia), Dyskretne uroki starosci (Polonia), Zmarszczki (Polonia, TV cable), Arrugues (catalán), Морщинки (Rusia) y Wrinckles (título en inglés para el resto del mundo).

País: España.

Año: 2011.

Director: Ignacio Ferreras.

Música: Nani García, Ignacio Ferreras, Álvaro Guevara.

Fotografía: David Cubero.

Montaje: Gemma Gassó.

Guion: Rosanna Cecchini, Ignacio Ferreras, Patrick Mullen (adaptación al inglés), Paco Roca (cómic original), Stephanie Sheh (versión en inglés), Ángel de la Cruz.

Intérpretes: Tacho González (voz de Emilio), Álvaro Guevara (voz de Miguel), Mabel Rivera (voz de Antonia), Raúl Dans (Voz de Xoán), Montse Dávila (voz de la nuera), Charo Díaz (voz de Emi), Isabel Vallejo (voz de Maite, mujer asistida), Carolina Vázquez (voces de Xoán niño y de la okupa), Xermana Carballido (voz de Dolores), Paco M. Barreiro (voz de Ramón, el locutor), Ana Maciñeiras (voz de Sol), Charo Pena (voz de Rosario, mujer asistida), Xabier Perdiz (voz de Martín), Antonio Rey (voz de Agustín, hombre asistido), Miguel López Varela (voz de Pellicer), Antón Olmos (voz de Esteban), Ana Lemos (voz de Eugenia), Matías Brea (voz en la escaleras).

Color: color.

Duración: 89 minutos.

Género: animación, drama, comedia.

Idioma original: castellano. gallego.

Productoras: Cromosoma TV produccions, Elephant in the Black Box, Perro Verde Films.

Sinopsis: Emilio y Miguel, dos ancianos recluidos en una residencia geriátrica se hacen amigos. Emilio, que padece una enfermedad de Alzheimer en fase inicial, cuenta de inmediato con la ayuda de Miguel y otros compañeros que tratarán de evitar que vaya a parar a la planta de los desahuciados. Su disparatado plan tiñe de humor y ternura el tedioso día a día de la residencia, pues para ellos acaba de empezar una nueva vida.

\section{Enlaces:}

https://www.filmaffinity.com/es/film189008.html https://www.imdb.com/title/tt1407052

\section{Trailer en español}

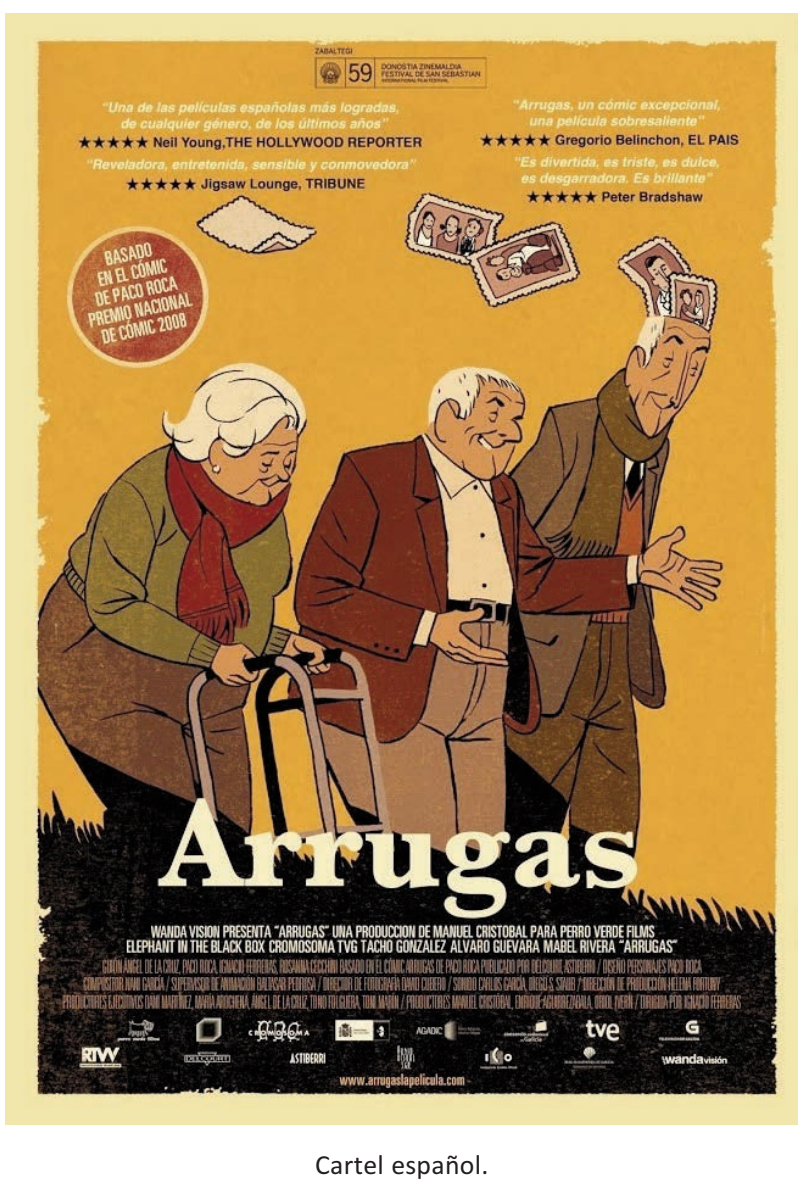

La enfermedad de Alzheimer en el cómic

Aun cuando la percepción social del cómic ya está cambiando, hay quienes todavía asocian esta palabra con un medio eminentemente enfocado al ocio y al entretenimiento, con un producto infantil, frívolo y poco serio.

Sin embargo, nos encontramos ante uno de los medios más eficaces para comunicar a diferentes grupos demográficos múltiples aspectos vinculados con la 
medicina y la salud. Así han sabido entenderlo instituciones y autores de cómics de diversos países, quienes han encontrado en el arte secuencial el modo de acercar a la sociedad la enfermedad de Alzheimer, sin ambages ni dramatismos, así como los estragos que provoca en los pacientes y en sus cuidadores, y también la vida de las residencias de ancianos de manera sensible, con algunas pinceladas de humor, pero sin caer en ningún momento en la caricatura.

En el contexto anglosajón, dentro del ámbito del cómic de autor para adultos, cabe destacar Tangles: a story about Alzheimer's, my mother and me (2010) de la canadiense Sarah Leavitt, obra traducida al alemán, francés y coreano, quien relata su historia personal y real como cuidadora de su madre, diagnosticada de Alzheimer a los 55 años, ese territorio desconocido donde su desorientada familia se estaba adentrando, devastador, extraño, pero también repleto de ternura y amor, como explica la propia autora canadiense en su página web1.

Aliceheimer's: Alzheimer's Through the Looking Glass (2012), de Dana Walrath, fue publicado por la Penn State University Press. Se trata de una crónica de los últimos años que esta autora estadounidense y su madre Alice, enferma de Alzheimer, pasaron juntas, "una crónica

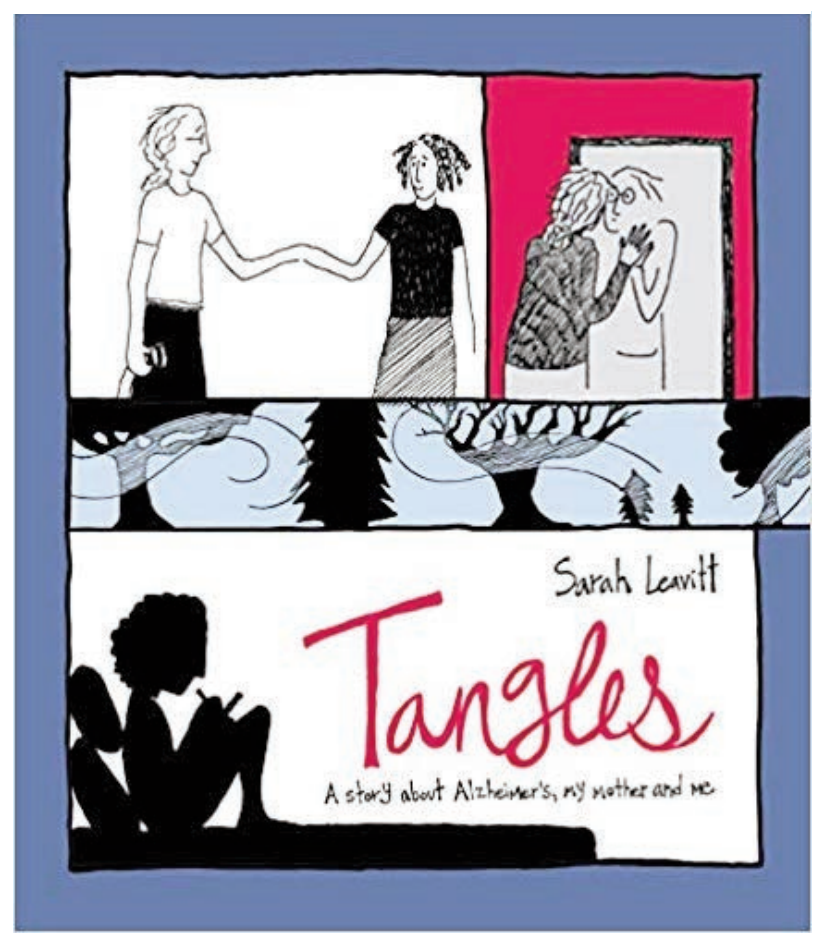

que se erige como un homenaje a la vida de Alice y proyecta una imagen de la enfermedad de Alzheimer y sus cuidados libres de estereotipos" 2 .

Antropóloga y profesora de la Facultad de Medicina de la Universidad de Vermont, Dana Walrath explica en el capítulo introductorio de su novela gráfica "que decidió contar en forma de cómic la historia del tiempo en que cuidó de su madre con Alzheimer porque, dado que las habilidades humanas para leer imágenes preceden a la adquisición del lenguaje, las narrativas que emplean imágenes tienen el poder de adentrarse profundamente en el subconsciente de quienes las leen, lo cual es especialmente positivo para aquellos ávidos lectores que, como Alice, desarrollan una enfermedad neurodegenerativa que deteriora su capacidad para el lenguaje"2.

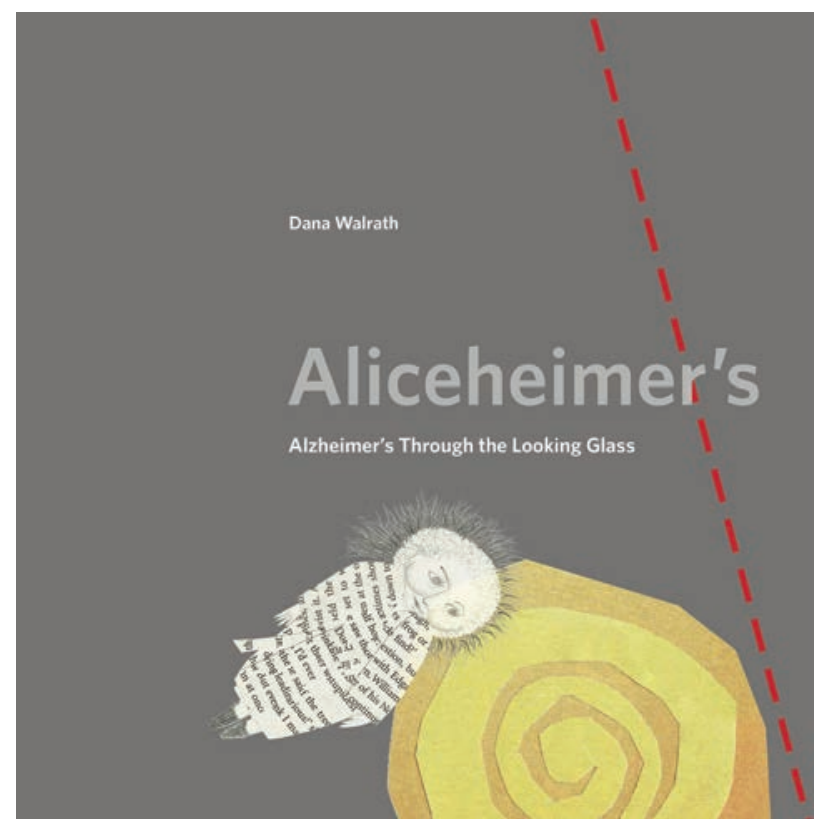

Para el público general, conviene citar la serie de hojas informativas en formato cómic producida por la organización neoyorquina CaringKind con el fin de prestar asesoramiento a las familias con un enfermo de Alzheimer y ayudarles en el cuidado y la atención al enfermo, varias editadas en español ${ }^{3}$.

También los cómics de la asociación alemana Alzheimer Forschung Initiative, que en su página web creada para los más jóvenes han editado cuatro webcómics, donde de la mano de los personajes Katja y Max explican qué es el cerebro, cómo funciona y en qué consiste la enfermedad que padece su abuela, Gisela ${ }^{4}$. 

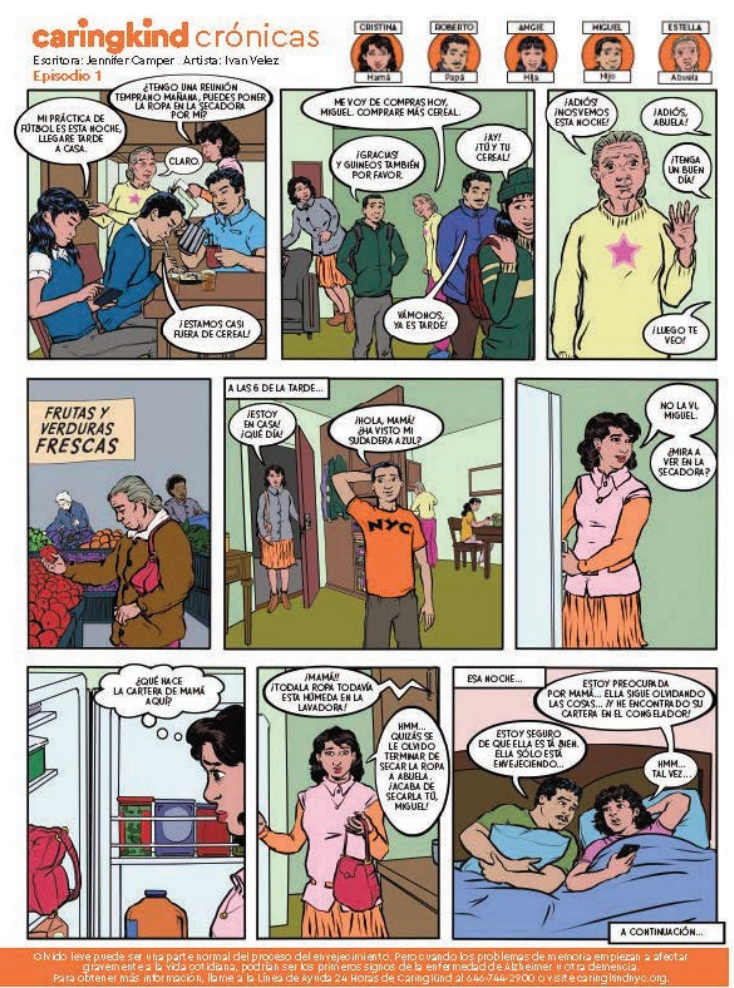

En España, hasta la fecha, disponemos de tres publicaciones de sumo interés tanto para la población infantil, juvenil y general como para los actuales y futuros profesionales sanitarios. Se trata de Arrugas (2007) de Paco Roca, Alzheimer: ¿qué tiene el abuelo? (2010), editado por la farmacéutica Lundbeck, y Tú, yo y el Alzheimer (2016) publicado por la Fundación ACE, narrativas gráficas que con singular elocuencia plástica y verbal consiguen interesar, deleitar, conmover y educar.

\section{Cómics para niños y adolescentes}

El esfuerzo por educar, informar y sensibilizar a los más jóvenes sobre temas médico-sanitarios a través del cómic no es un fenómeno exclusivo de nuestros días, sino que se remonta a la segunda mitad del siglo pasado. Así, disponemos de cómics de corte divulgativo que relatan diversos y apasionantes episodios de la historia de la medicina de la mano de sus protagonistas, entre los que cabría destacar Louis Pasteur. Benefactor de la Humanidad (1956) y Ramón y Cajal, el sabio (1960), ambos pertenecientes a la serie Vidas Ilustres de la editorial mexicana Novaro.

También existen otros, de tipo divulgativo, como Dos glóbulos en apuros (1978), de la colección Grandes
Aventuras de la editora ESCO (Centro Internacional de Estudios para la Escuela y la Comunicación), dirigidos a un público escolar, que narra de manera divertida y pedagógica el funcionamiento del cuerpo humano.

Asimismo, se editaron cómics para la promoción y la educación en el ámbito de la salud, y no solo en español, como Las aventuras de Salustín en el país de la salud (1987), que formó parte de una campaña de salud destinada a los niños que cursaban la EGB (Enseñanza General Básica), distribuido en colegios y centros sanitarios "con el fin de informar al niño sobre la salud, su cuidado, mantenimiento y la prevención de las enfermedades" 5 , sino también en catalán, como El tabac i els joves. El cas Fumarola (1983), realizado por el Departament de Sanitat i Seguretat Social de Catalunya, que se iniciaba con cuatro páginas con información detallada sobre el tabaco y sus consecuencias para la salud.

Conscientes del potencial comunicativo del medio para divulgar, informar, educar y sensibilizar a la población infantil y juvenil sobre temas relacionados con

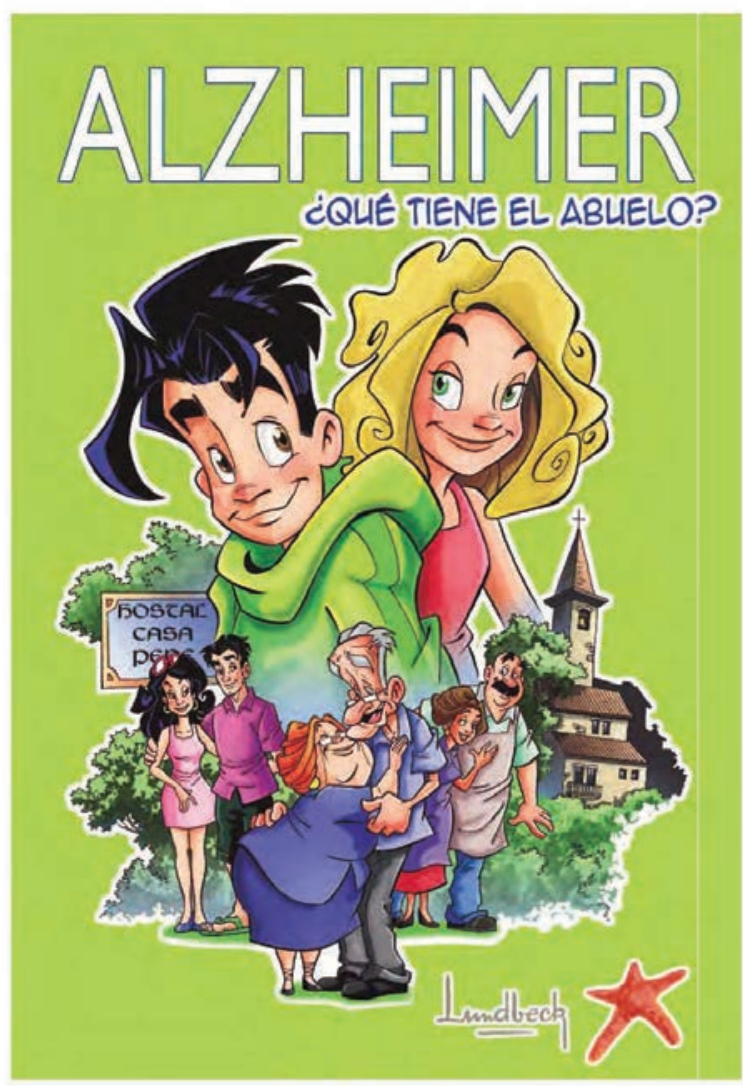




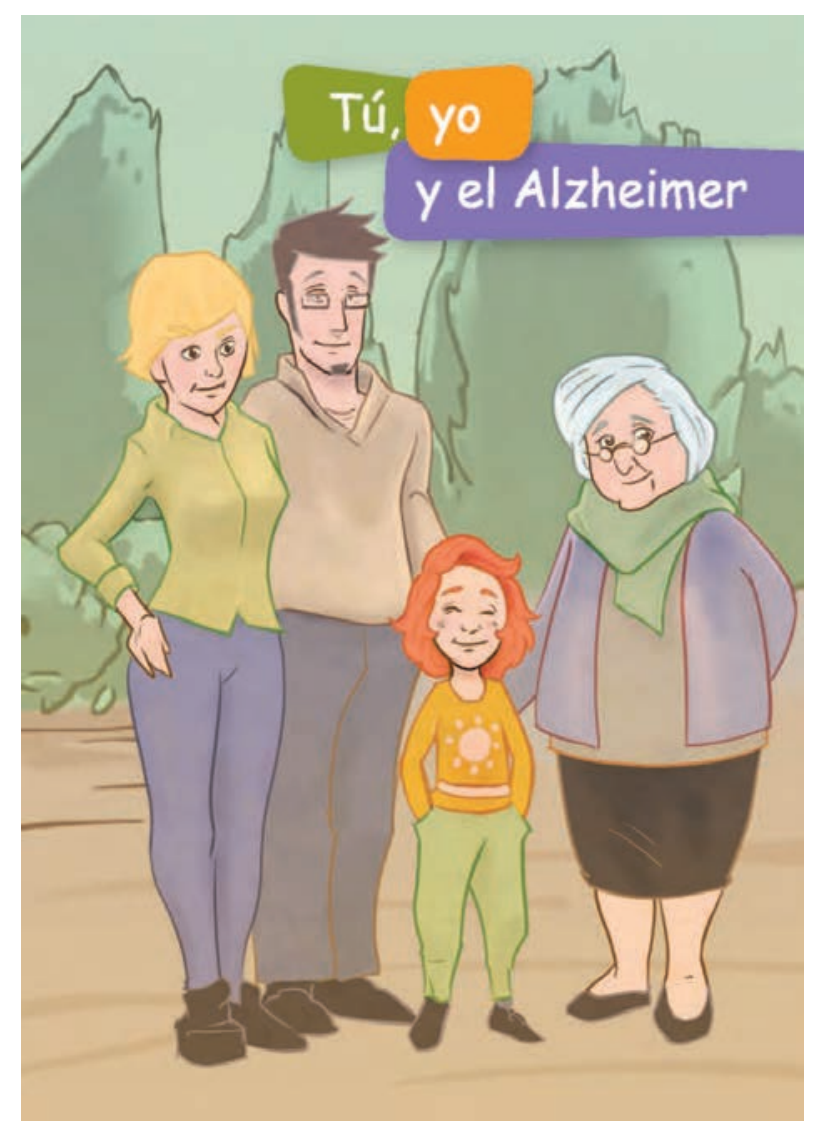

la medicina y la salud, y gracias a los avances tecnológicos, el número de entidades públicas, privadas e iniciativas particulares que apuestan por el cómic ha ido aumentando espectacularmente a lo largo de más de sesenta años.

Los soportes de edición-papel, digital, webcómic - son diversos y numerosos, así como los temas contemplados: asma, enfermedades de transmisión sexual (ETS), diabetes, epilepsia, anemias minoritarias, Parkinson, cardiopatías congénitas, esquizofrenia, artritis idiopática juvenil, trastorno por déficit de atención e hiperactividad (TDAH) y enfermedad de Alzheimer.

No pocos menores son y serán testigos de la repercusión y los estragos de esta afección en la persona que la padece, en quienes le rodean, y quizás en ellos mismos como receptores indirectos. Cómo explicar a niños y adolescentes qué es el Alzheimer, qué implica padecer esta enfermedad y de qué manera ser útiles para el enfermo son cuestiones para cuyas respuestas no todos los padres están preparados. Es más, según una tesis doctoral de la Universidad de Barcelona, el 37\% de estos niños demostró miedo por la enfermedad, mientras un 50\% confesó avergonzarse de que sus amigos supieran que sus abuelos estuvieran enfermos ${ }^{6}$.

La diversidad de recursos disponibles en Internet sobre esta enfermedad, sobre el valor de la documentación para conocer cómo cuidar al enfermo y apoyarlo, son contenidos presentes en un buen número de materiales destinados a los pacientes, sus familiares y cuidadores. Pero hacer comprender a un joven la necesidad de que esté bien informado e involucrarlo en dicha labor no resulta una tarea fácil. De ahí el interés que tienen determinados cómics como Alzheimer: ¿qué tiene el abuelo? y Tú, yo y el Alzheimer, destinados a facilitar a los más jóvenes la comprensión del alcance de esta enfermedad y asumirla, además de ayudar a quienes la padecen y a sus cuidadores.

Alzheimer: ¿qué tiene el abuelo?77 es una bellísima publicación editada en 2010 por el laboratorio farmacéutico Lundbeck en castellano, catalán, gallego y euskera, contando en su elaboración con la participación de la neuróloga y directora médica de la Fundación ACE, la doctora Mercè Boada. Concebido para niños y adolescentes de entre 10 y 16 años de edad, narra la historia de Ramón, un anciano que comienza a sufrir los primeros síntomas de Alzheimer, y de su nieto Julio, un joven que durante las vacaciones estivales en el pueblo de sus abuelos irá descubriendo las consecuencias de la pérdida de memoria, los problemas de orientación, la dificultad para planificar las tareas o los cambios de carácter de su abuelo. De esta manera, aprenderá la importancia de colaborar en el diagnóstico y cómo ayudar al enfermo mediante juegos, ejercicios de memoria para que se mantenga activo, estimulando así su atención y concentración. De este cómic se repartieron unos 10000 ejemplares entre especialistas y asociaciones para que los entregaran a los familiares de los pacientes.

Tú, yo y el Alzheimer 8 fue publicado en 2016 por la Fundación ACE y el laboratorio farmacéutico Kern Pharma, en el que también colaboró la doctora Mercè Boada. Nació destinado a niños entre los 6 y 12 años, con el objetivo de afrontar con mayor conocimiento el diagnóstico de esta enfermedad que pudieran padecer personas de su entorno más cercano, como la abuela de Raquel, la protagonista de este cómic, así como para animarles a colaborar en la ayuda de los pacientes en aquellas actividades básicas de la vida cotidiana (comer, caminar, levantarse), en actividades lúdicas y de distracción (comunicarse con ellos, hacerles compañía) y a ejercitar 


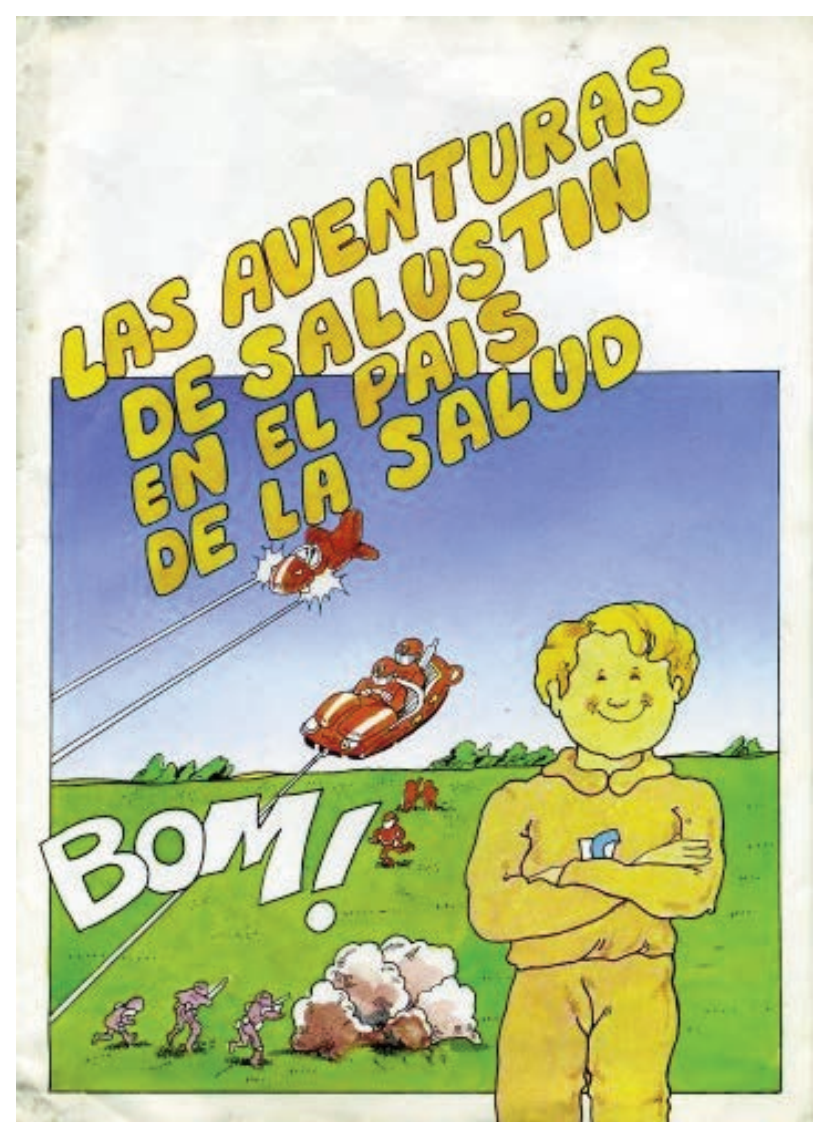

la memoria, tal y como quedan plasmadas en esta publicación repleta de ternura, que además incluye dos secciones para que los jóvenes lectores ejerciten los contenidos narrados en el cómic.

Con una tirada de 20000 ejemplares, además de distribuirse entre los neurólogos y las farmacias adheridas a este proyecto para que los hiciesen llegar a las familias con un miembro afectado de Alzheimer, con motivo del Día Mundial de esta enfermedad Kern Pharma distribuyó 800 copias entre 40 colegios de cinco comunidades autónomas (Andalucía, Asturias, Catalunya, Comunidad Valenciana y Galicia) con la intención de sensibilizar a los niños sobre ella y para que pudiesen hablar libremente del Alzheimer con sus maestros y compañeros.

Se trata, en definitiva, de dos cómics deliciosos que nos sumergen en una experiencia personal del enfermo de Alzheimer a través de la mirada inocente de unos niños que la desconocen y que han de aprender a convivir con ella.

\section{Arrugas de Paco Roca: haciendo visible lo invisible}

La historia del cómic Arrugas ${ }^{9}$ está ambientada en una residencia de ancianos. Narra la amistad entre Emilio, recién llegado a la institución en un estado inicial de Alzheimer, por decisión de su hijo y de su nuera, y Miguel, su compañero de habitación, que se convertirá en su amigo y guía para enseñarle los entresijos del geriátrico, presentarle a los demás ancianos, e intentar evitar, sin éxito, que Emilio termine ingresado en la planta superior, el temido piso que alberga a los internos asistidos, ancianos incapaces ya de valerse por sí mismos. Junto a esta trama principal, esta obra pensada para el público en general recoge asimismo un sinfín de episodios, hilarantes muchos de ellos, relacionados con los otros residentes y sus cuidadores.

Siendo la vejez y la enfermedad de Alzheimer sus hilos conductores, Arrugas es una obra del dibujante, ilustrador y autor de cómics Paco Roca, en este caso un cómic que ha obtenido un enorme éxito de crítica y

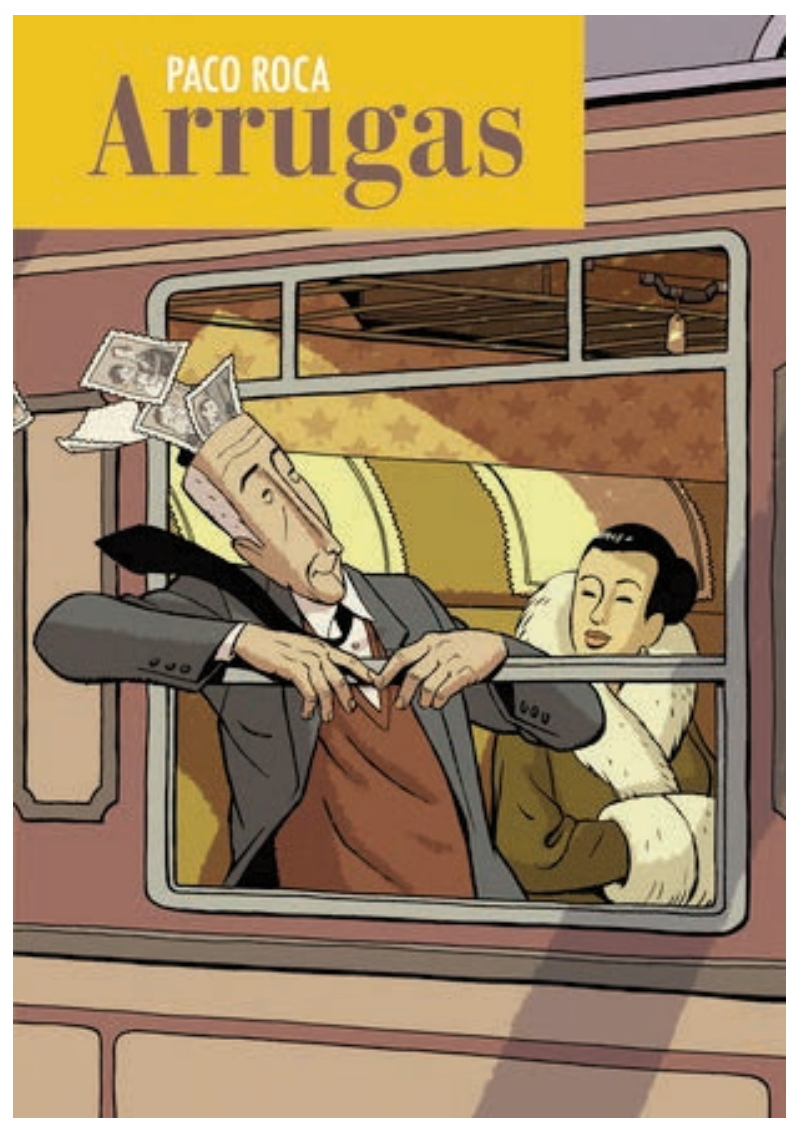


público, superando la friolera de 72000 ejemplares vendidos. Ha sido galardonado con numerosos premios, tanto nacionales como internacionales -Premio Nacional de Cómic en 2008-, traducido a múltiples idiomas (gallego, catalán, inglés, alemán, chino, portugués, holandés, italiano, finlandés, ruso).

En una obra posterior, realizada al alimón con el también dibujante de cómics Miguel Gallardo10, Paco Roca explicaba las razones que le impulsaron a crear un relato gráfico sobre la vejez y el Alzheimer. La primera fue por sus padres, que ya se iban haciendo mayores, y en cierta medida deseaba homenajearlos con esta novela gráfica. La segunda, a raíz de un encargo como ilustrador publicitario, tras pedirle un cliente que eliminara a los ancianos que previamente había dibujado en un cartel al considerarlos antiestéticos. Este hecho le impulsó a reflexionar por qué la vejez no es un tema principal en la literatura, el cine y el cómic, resultando más bien escasas las historias centradas especialmente en las personas mayores. La tercera razón se refiere al impacto emocional causado al conocer que el padre de un amigo suyo padecía Alzheimer. Todos ellos argumentos más que suficientes para sentir la necesidad de escribir y dibujar una historia sobre la vejez y el Alzheimer, tal y como explicó el propio Paco Roca en una entrevista concedida al dibujante y crítico de cómic Pepo Pérez en 200911.

Arrugas es una historia de ficción que exhala un aire de verosimilitud gracias al minucioso trabajo de documentación llevado a cabo por el autor, que visitó personalmente varias residencias de ancianos donde se entrevistó con médicos, enfermeros, familiares y personas mayores que allí habitaban. De la misma manera, recopiló anécdotas de amigos suyos cuyos padres vivían en residencias o padecían Alzheimer. $\mathrm{Y}$ es, tal y como afirma González Cabeza12, "esa realidad dentro de la ficción es la que lo convierte en un texto valioso desde el punto de vista antropológico y patográfico". A todo ello cabe añadir el punto de vista emocional y afectivo, pues el personaje de Emilio "encarna a los padres y abuelos de muchos de nosotros, y también nos hace pensar en nosotros, en lo que nos puede esperar, en la soledad, la rabia y la impotencia de tener que depender de otros, como si fuésemos niños..."13.

Arrugas consigue humanizar la vejez y la enfermedad, centrando nuestra atención en un grupo demográfico frecuentemente ignorado por la cultura popular. Son estos elementos los que precisamente convierten a este cómic en una obra de suma utilidad, en especial para los familiares de las personas con Alzheimer, los cuidadores y los profesionales sanitarios.

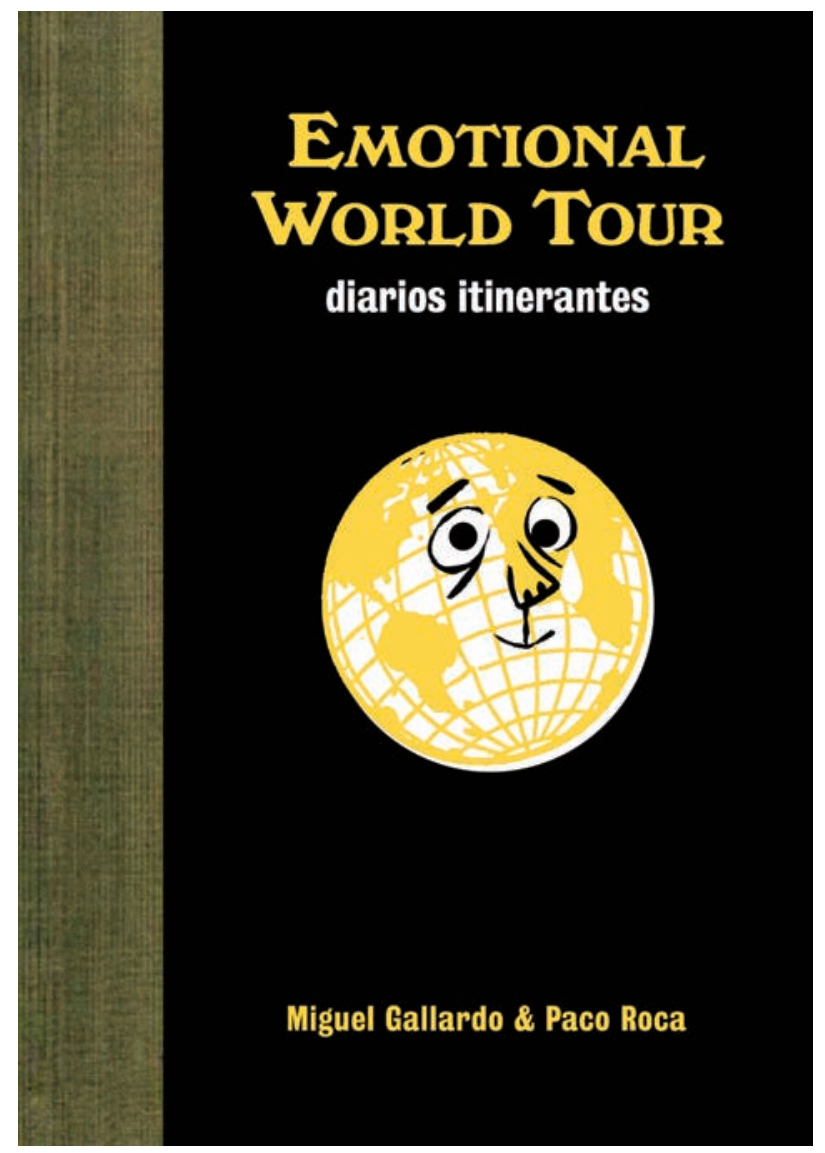

A los primeros - además del abordaje de la enfermedad desde una perspectiva clínica, que contribuye a un mejor conocimiento de la misma- porque su lectura les proporciona cierta catarsis tras verse reflejados en una historia y sentirse parte de una comunidad, amén de ayudarles a hacer entender a las personas de su entorno por todo lo que han pasado, o sus experiencias como cuidadores, como muy bien quedó reflejado en los comentarios de los lectores de su obra durante la firma de ejemplares -episodios ilustrados en el álbum Emotional World Tour-, algo propio por otra parte de este tipo de cómics de autor donde la enfermedad o la carencia de salud, así como todo lo que esto conlleva, constituyen el eje temático ${ }^{14}$.

Respecto a los profesionales sanitarios, Arrugas les posibilita convertirse en testigos desde la experiencia personal del enfermo de Alzheimer, además de lo que supone vivir en una residencia - la soledad, el desarraigo, la monótona rutina-, pero también el deseo de autonomía y la importancia de sentirse acompañado, de la amistad, del cariño, que tanto amparo aporta a los enfermos. 


\section{Inés Gouzález Cabeza \\ lmágenes de la enfermedad en el cómic actual}

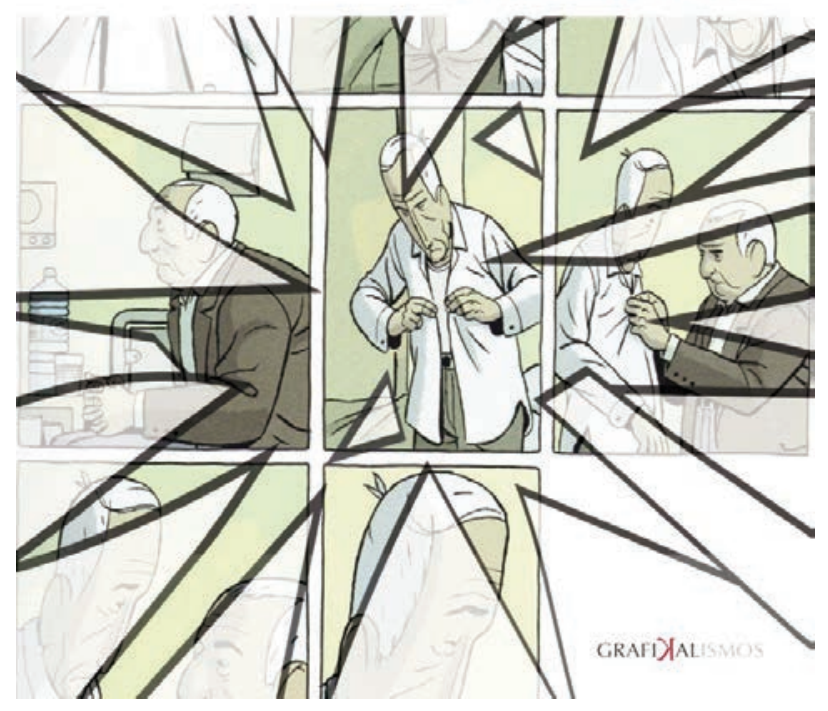

No es de extrañar que el médico británico lan Williams, autor de cómics, creador del término y de la página web Graphic Medicine ${ }^{15}$, sea uno de los defensores más destacados del uso del cómic dentro de la formación humanística de los profesionales sanitarios. Hace años recomendó en la Universidad de Puerto Rico la incorporación de Arrugas a los programas de humanidades médicas, argumentando que los médicos suelen quedarse en la parte más práctica de la medicina, olvidando cómo determinadas enfermedades, como por ejemplo el Alzheimer, minan el entorno familiar. Atender el lado humano es también un deber médico.

Los cómics autobiográficos o semiautobiográficos que abarcan este tipo de temáticas, denominados patografías gráficas ${ }^{14}$, son de gran relevancia para el aprendizaje cognitivo y afectivo, ya que ayudan a ver la profesión médico-sanitaria y la enfermedad, con su componente emocional, desde el punto de vista propio de los pacientes. Enfrenta a los estudiantes y sanitarios en ejercicio ante sus particulares perjuicios, sesgos e ideas preestablecidas; y fomenta la empatía, algo esencial para ser un buen profesional16. Desde que Michael Green ${ }^{17}$, profesor del Departamento de Humanidades y Medicina Interna de la Facultad de Medicina de Pensilvania, introdujera en 2009 el seminario Historias gráficas y narrativas médicas, las patografías gráficas comenzaron a formar parte de los elementos incorporados como herramientas didácticas por las humanidades médicas. Otros profesores, animados por sus prebendas docentes, se han lanzado asimismo a su empleo, bien a través de seminarios como en la Facultad de Medicina Feinberg de Chicago, en las universidades de Toronto y Massachusetts, bien en forma de actividades enmarcadas en el contexto de una determinada asignatura ${ }^{18,19}$.

Empleo que además se ha visto favorecido por la proliferación de este tipo de cómic y la variedad de temas tratados. A modo de ejemplo, destacamos algunos de ellos, ya sean originales o versiones en castellano de otros idiomas, que podemos encontrar en el mercado español: Lucille (anorexia), María y yo; María cumple 20 años (autismo), Yo, gorda; Gorda (bulimia), Don Barroso (cáncer de colon), Los silencios de David (cáncer de laringe), Cancer Vixen. Mi lucha contra el cáncer; Alicia en un mundo real; La historia de mis tetas; Que no, que no me muero (Cáncer de mama), Rosa Y Javier (drogadicción), Epiléptico. La ascensión del gran mal; Ausencias (epilepsia), Piltrafilla; De tripas y corazón (enfermedad de Crohn), Un adiós especial; La ternura de las piedras (envejecimiento, final de la vida, cuidados paliativos), Fantasmas (fibrosis quística), Francine se desarregla (menopausia), Una posibilidad (parálisis cerebral), Super Sorda (pérdida de audición), Shino no es capaz de decir su propio nombre (tartamudez), El día de la victoria; Majareta. Manía depresión; Miguel Ángel y yo: Cara o cruz (trastorno bipolar), Trágame entera; Las voces y el laberinto; Desmesura (Una historia cotidiana de locura en la ciudad) (TOC, esquizofrenia), El paréntesis (tumor cerebral) o Píldoras azules; Pedro y yo; Trapicheos en la Segunda Avenida (sida).

El mérito de Arrugas, Alzheimer: ¿qué tiene el abuelo? y Tú, yo y el Alzheimer no radica exclusivamente en hacer visible lo invisible -la experiencia personal del enfermo de Alzheimer, la ancianidad, la soledad o el desarraigo-, en recalcar la importancia de la amistad, del cariño, que tanto apoyo representa para los enfermos, en fomentar la relación entre abuelos y nietos, o en explicar de manera sencilla en qué consiste la enfermedad de Alzheimer desde el punto de vista clínico, sino en haber optado por la narrativa gráfica para su abordaje.

La enfermedad de Alzheimer en el cine: Arrugas (2011) de Ignacio Ferreras

El Centro de Referencia Estatal de atención a personas con enfermedad de Alzheimer y otras demencias, del Instituto de Mayores y Servicios Sociales (IMSERSO), dependiente del Ministerio de Sanidad, Servicios Sociales e Igualdad del Gobierno de España, publicó en 


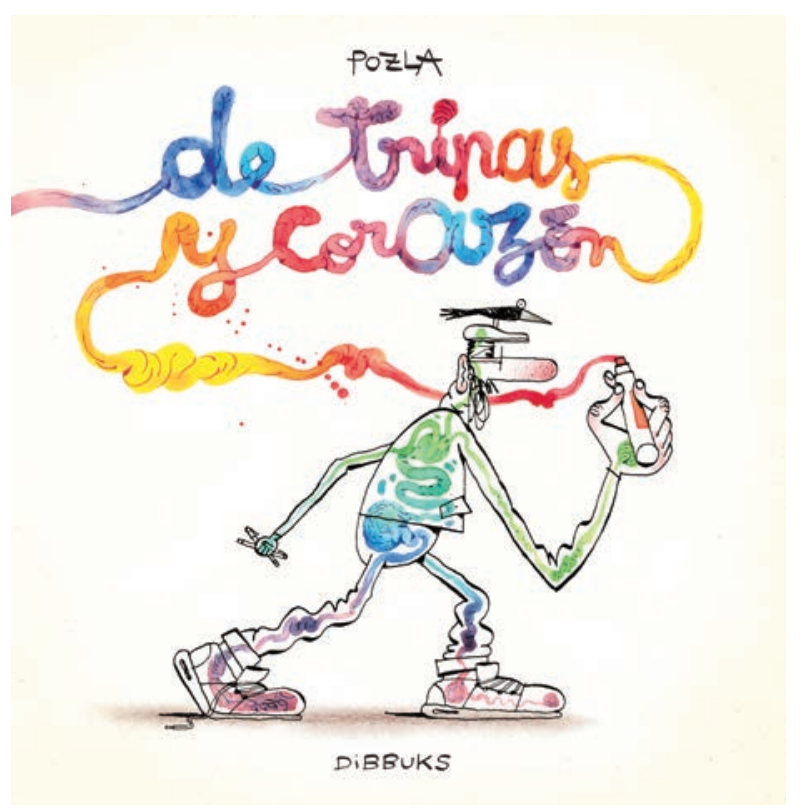

2017 una interesante guía de recursos documentales titulada La Enfermedad de Alzheimer en el Cine ${ }^{20}$, que incluía 38 títulos de películas con sus correspondientes sinopsis y fichas técnicas.

Una de ellas es Arrugas (2011) de Ignacio Ferreras, la adaptación cinematográfica del exitoso cómic homónimo original del valenciano Paco Roca (1969), galardonado con el Premio al Mejor Guión y Mejor Obra Española en el Salón de Barcelona de 2008, Premio Nacional del Cómic de 2008, traducido a múltiples idiomas y publicado en España por las editoriales Astiberri y Delcourt, a nivel internacional.

Considerando la excelsa calidad del cómic, una parte nada desdeñable de la crítica especializada ha considerado tan brillante como innecesaria su adaptación a la gran pantalla, debido a la estrecha participación de su autor, Paco Roca, en el guión y en la supervisión cinematográfica. Esta particularidad situaría al mismo nivel, por lo menos, la apreciación de las viñetas y los fotogramas. Al igual que el cómic, la película fue recompensada en 2011 con sendos Premios Goya: a la Mejor Película de Animación y al Mejor Guion Adaptado. Precisamente la inusitada influencia de la presencia visual del autor significa que leer el cómic o ver la película pudiera ser lo mismo ${ }^{21}$.

\section{El cine español de animación}

Al contrario de lo ocurrido en el mundo de la televisión, donde existe una infinidad de obras destacables, el cine de animación español, en especial el destinado preferentemente a un público adulto, podría parecer más bien escaso, tanto en cantidad como en calidad.

El propio Ignacio Ferreras fue el guionista y director del corto de animación How to cope with death (2002), una inteligente aproximación al mundo de la vejez y la muerte, producido por la británica Tandem Films.

Previamente a Arrugas, la nominada para el Óscar Chico y Rita (2010) de Fernando Trueba, Javier Mariscal y Tono Errando, quizás sirviera de acicate para que otros directores cinematográficos se aventuraran con este tipo de producciones. Prueba de ello podrían ser ejemplos más recientes de cine de animación para adultos como Un día más con vida (2018) de Raúl de la Fuente y Damián Nenow, Premio Goya a la Mejor Película de Animación, o Memorias de un hombre en pijama (2018) de Carlos FerFer, 2018), basada asimismo en otro cómic original de Paco Roca y masacrada sin piedad por la crítica especializada, que incluso ha calificado su animación como pobretona llegando a tildar a la cinta de rancia y machista22.

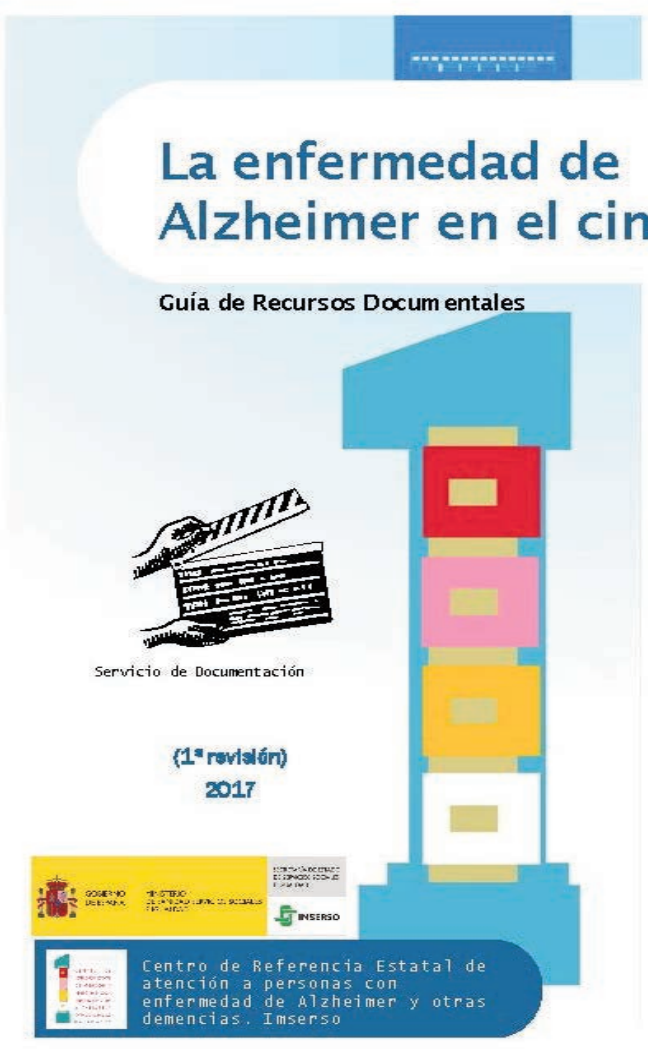




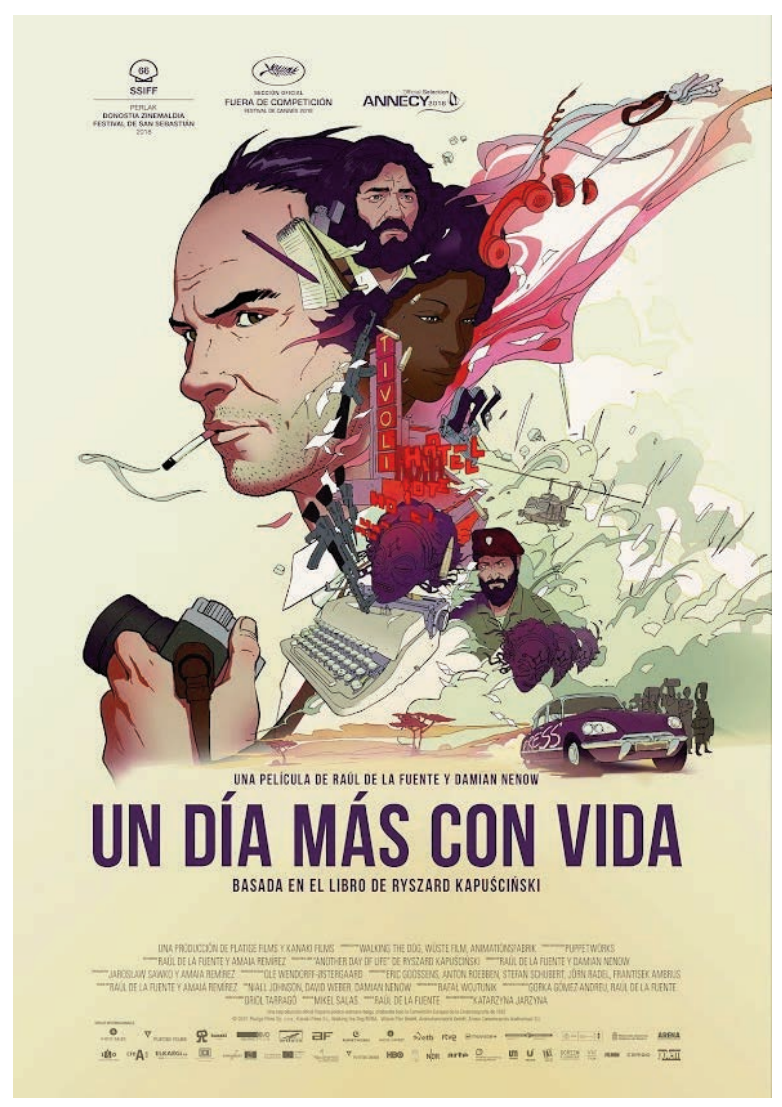

¿Cómic versus cine?

Muchos críticos comentan, después de haber leído el cómic Arrugas, que la película pierde fuerza y emoción, no alcanzando a atrapar al espectador tanto como lo hace la novela gráfica.

El cómic es narrativa dibujada, lo que resulta de gran relevancia para el aprendizaje cognitivo y afectivo. La lectura de textos narrativos estimula la emoción, y este es uno de los factores más importantes en la comprensión de la información y en el recuerdo que se tiene posteriormente de ella ${ }^{23}$. Pero si además se trata de la lectura de narrativas gráficas, como es el caso del cómic, la comprensión y el recuerdo son todavía más potentes, al recibir información verbal y no verbal de manera simultánea14.

El cómic, por otra parte, favorece la identificación del lector con el personaje. Como explican los teóricos del cómic 24,25 , el dibujo minimalista nos permite proyectarnos en el personaje, identificarnos con él, fomentando la empatía. No es de extrañar que uno de los alumnos de la asignatura Fundamentos de Fisioterapia del primer curso del Grado de Fisioterapia de la Facultad de Ciencias de la Salud de la Universidad de Almería afirmara tras la lectura de Una posibilidad entre mil (2009) de Miguel Á. Giner Bou y Cristina Durán, que narra la historia y evolución de Laia, hija de los autores del cómic, tras sufrir una parálisis cerebral a las pocas horas de nacer, lo siguiente: "He llegado a sentirme un personaje más del cómic, cómo me influían las actuaciones de los profesionales, las alegrías y las tristezas de la familia... Ha sido una experiencia diferente y preciosa, me ha encantado"19.

Asimismo, el cómic demanda una lectura activa y participativa por parte del lector. Como lenguaje, emplea mecanismos de gran carga simbólica que el lector debe descifrar para construir sentido, como por ejemplo el estilo de los globos o bocadillos, los cartuchos o cartelas, las líneas cinéticas, las onomatopeyas, las metáforas visuales, la calle, que es el espacio que hay entre los paneles y donde el lector pone en movimiento la narración al tener que llenar con la imaginación los espacios en blanco dejados deliberadamente por el creador del cómic. Son recursos que le llevan a sumergirse y verse envuelto en el relato. O sea, el cómic no describe todo en el plano textual, sino que deja un cierto margen de interpretación, conduciendo al lector a una mayor implicación.

Arrugas (2011) de Ignacio Ferreras cuenta con una magnífica producción, que además respeta el estilo gráfico de Paco Roca, cuya responsabilidad se limitó a la primera fase de adaptación del cómic al guion cinematográfico y al diseño de los personajes, para que su estética resultase lo más parecida al cómic.

Determinados detalles de la película, que en el cómic quedaban a expensas de la imaginación del lector, como por ejemplo el peculiar acento de Miguel -aprovechándose de ese tópico universal sobre la supuesta vocación embaucadora argentina-, la tragicomedia ocurrida en la piscina o el precioso flashback esclarecedor de la historia de Dolores y Modesto, además de la excelente partitura del compositor, músico y productor musical Nani García, contribuyeron a añadir un meritorio plus a la película.

En Arrugas, la enfermedad de Alzheimer sirve de entramado para mostrarnos cómo todo lo que nos rodea está sujeto al inexorable paso del tiempo, incluso la vejez. Pero esta propuesta rehúye de los tópicos y el tremendismo, no resulta ni desangelada ni triste, sino que aprovecha una serie de elementos más o menos cómicos para ganarse el corazón del espectador. Sin descuidar al resto de los personajes que habitan en la residencia de ancianos, los vaivenes de la amistad entre Emilio y Miguel se convierten en el motor adicional de la historia ${ }^{26}$, los dos únicos personajes que no permanecen estáticos durante 
la película, pues la evolución de la enfermedad de Emilio le conducirá inexorablemente hacia la planta superior, donde languidecen los ancianos dependientes, mientras Miguel irá adquiriendo una mayor conciencia, de manera agridulce, de que se está enfrentando a los últimos episodios de su existencia.

Algunos autores se han mostrado más partidarios de una versión cinematográfica del cómic original protagonizada por actores y actrices de carne y hueso ${ }^{27}$, entendiendo que la mesura y la austeridad de los trazos de Paco Roca resultan castigados cuando se les añaden movimientos cinematográficos. De esta manera, perderían el sutil preciado simbolismo poético que intentan recuperar otros fundamentos del film, como por ejemplo la anteriormente reseñada banda sonora del coruñés Nani García.

Después de leer el cómic o ver la película, lector y espectador quedan hermanados en el miedo al deterioro y la muerte, si bien cuando estos momentos se aproximan, podemos llevarnos sorpresas impactantes ${ }^{28}$. Definitivamente, una u otra tarea nos habrá hecho más humanos y mejores personas que antes de leer o contemplar.

Finalmente, el papel del médico también difiere entre cómic y película, desvelándole en el primero a Emilio, de una manera seria y profesional, el diagnóstico y el pronóstico de su enfermedad, mientras que en la versión cinematográfica es el propio Emilio el que descubre su destino infiriendo que comparte la misma medicación con el dependiente Modesto.

\section{Referencias}

1. Sarah Leavitt [Internet]. Tangles: A Story About Alzheimer's, My Mother and Me. 2. González Cabeza I. Autobiografías sobre cuidados: repensando la catarsis. Revista Tebeosfera. Tercera época, 9 [Internet]. 18 de diciembre de 2018. [consultado el 11 de marzo de 2019].

3. Camper J, Vélez I. CaringKind Crónicas [Internet]. Episodio 1. [consultado el 11 de marzo de 2019].

4. Alzheimer Forschung Initiative. Afi-Kids. Das Gehirn, Die Reise ins Gehirn, Oma wird vergesslich. [consultado el 11 de marzo de 2019].

5. Jiménez Pérez F. Una campaña de salud pública dirigida a niños de EGB. Escuela Española 1987;[2865]:7 [Internet].

6. Megido Badía MJ. ¿Cómo viven los nietos la enfermedad de Alzheimer de sus abuelos? Estudio cualitativo en Atención Primaria [tesis doctoral]. Barcelona: Universidad de Barcelona: 2014

7. Alzheimer. ¿Qué tiene el abuelo? Barcelona: Saned; 2010

8. Tú, yo y el Alzheimer. Madrid, Saned; 2016.

9. Roca P. Arrugas. Bilbao: Astiberri Ediciones; 2007.

10. Gallardo M, Roca P. Emotional World Tour, diarios itinerantes. Bilbao: Astiberri Ediciones; 2009.

11. Pérez P. Entrevista a Paco Roca: la vida es sueño. Guíadelcómic.es [Internet]. Marzo 2009. [consultado el 11 de marzo de 2019].

12. González Cabeza I. Imágenes de la enfermedad en el cómic actual. León: Eolas Ediciones; 2017. p. 51.

13. Bazán Coquis A. Universo Cómic: Del Alzheimer a la nostalgia: dos obras de Paco
Roca. El Comercio [Internet]. 4 de septiembre de 2017. [consultado el 11 de marzo de 2019].

14. Mayor Serrano MB. Qué es la medicina gráfica. Revista Tebeosfera. Tercera época, 9 [Internet]. 18 de diciembre de 2018. [consultado el 11 de marzo de 2019]. 15. Williams I. Why "Graphic Medicine"? Graphic Medicine [Internet]. [consultado el 11 de marzo de 2019].

16. Mayor Serrano MB. El cómic como recurso didáctico en los estudios de medicina. Manual con ejercicios. Barcelona: Fundación Dr. Antoni Esteve; 2016.

17. Green MJ, Myers KR. Graphic medicine: use of comics in medical education and patient care. BMJ. 2010;340:c863.

18. Muzumdar J. Use of comic book to assist student learning of dimensions of patient-centered care. Inov Pharm. 2016;7(4): article 2.

19. Rocamora Pérez P, López Liria R, Aguilar Parra JM, Padilla Góngora D, Díaz López MP. El cómic como herramienta didáctica en Ciencias de la Salud. Revista Tebeosfera. Tercera época, 9 [Internet]. 18 de diciembre de 2018. [consultado el 11 de marzo de 2019].

20. Centro de Referencia Estatal de atención a personas con enfermedad de Alzheimer y otras demencias. Servicio de Documentación. Instituto de Mayores y Servicios Sociales (IMSERSO). La enfermedad de Alzheimer en el cine. Guía de Recursos Documentales. Madrid: Secretaría de Estado de Servicios Sociales e Igualdad. Ministerio de Sanidad, Servicios Sociales e Igualdad. Gobierno de España; 2017.

21. Benítez S. Cómic en cine. Arrugas de Ignacio Ferreras. Espinof [Internet]. 22 de junio de 2015. [consultado el 11 de marzo de 2019].

22. Belategui O. Los problemas de Paco Roca con las mujeres. El Correo [Internet]. 4 de enero de 2019. [consultado el 11 de marzo de 2019].

23. Baños JE, Guardiola E. La literatura en la docencia médica. Mètode Science Studies Journal 2018; [96]:47-53.

24. McCloud, S. Understanding comics: the invisible art. Nueva York: Harper Collins; 1994.

25. Williams I. Graphic medicine. Hektoen International Journal [Internet]. 2012:4,(1). [consultado el 11 de marzo de 2019].

26. Zorrilla M. Arrugas, una joya a descubrir. Espinof [Internet]. 26 de enero de 2012. [consultado el 11 de marzo de 2019].

27. Moral J. Arrugas. Ensayo sobre la vejez. El Espectador Imaginario [Internet]. Abril de 2012;[31]. [consultado el 11 de marzo de 2019].

28. De la Calle Ysern M. Reseña de la película Arrugas (2011). Revista Clínica Contemporánea [Internet]. 2017; 8(1): E8, 1-2. [consultado el 11 de marzo de 2019].

Miguel Abad Vila. Licenciado en Medicina por la Universidad de Santiago de Compostela. Doctor en Medicina por la Universidad de Santiago de Compostela). Diplomado en Salud Pública. Máster en Gestión Sanitaria por la Universidad de Vigo. Máster en Derecho Sanitario por la Universidad de Castilla La Mancha. Médico de Familia en el Centro de Saúde "Novoa Santos", Servizo Galego e Saúde, Ourense. Colaborador habitual de "La Región" (Ourense) y "Atlántico Diario" (Vigo). Autor de los blogs "Cartas de Aloysius" y "MEDYCINE".

María Blanca Mayor Serrano. Especialista en divulgación y comunicación médico-sanitaria. Doctora en Traducción Universidad de Granada, Máster en Terminología Universidad Pompeu Fabra de Barcelona. Autora del libro El cómic como recurso didáctico en los estudios de medicina. Manual con ejercicios. Barcelona: Fundación Dr. Antonio Esteve; 2016. Coordinadora y coautora del monográfico Medicina y cómic para la revista Tebeosfera, 2018. 